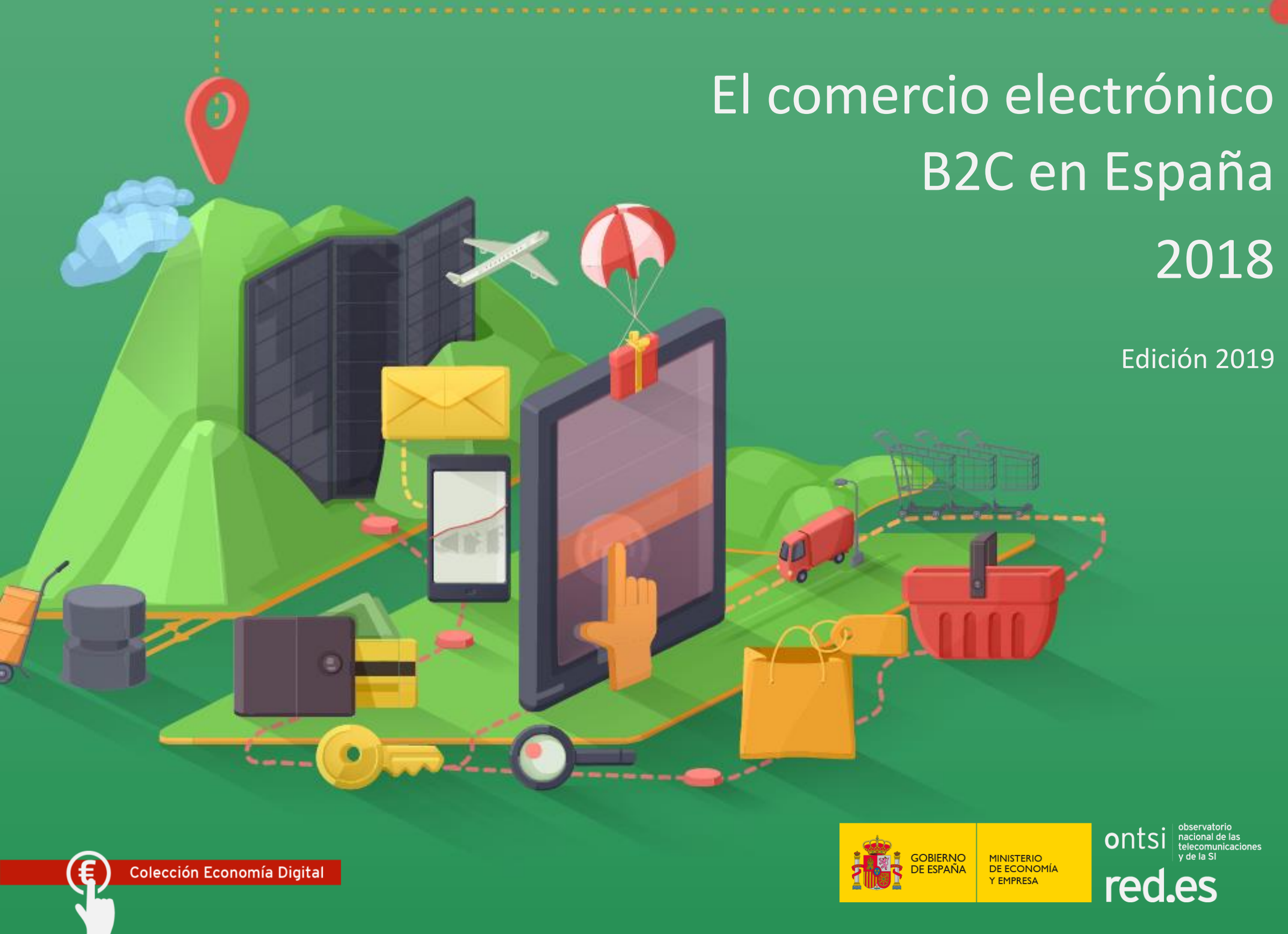




\section{Principales cifras}

Volumen de negocio; porcentaje de internautas y compradores; evolución temporal.

\section{Perfil sociodemográfico}

Perfil sociodemográfico de internautas, compradores y no compradores (sexo, edad, estudios, clase social y hábitat).

\section{Indicadores de compra}

Frecuencia y número de procesos de compra; productos comprados y su variación anual; formas alternativas de compra (móvil, contenidos digitales y comercio $\mathrm{C} 2 \mathrm{C}$ ); problemas en las compras; devoluciones y reclamaciones.

\section{Indicadores de gasto}

Gasto medio anual; distribución del gasto; gasto por tipo de producto; medios de pago; sitios de compra.

\section{Impulsores y frenos}

Impulsores del comercio electrónico; frenos del comercio electrónico: Aspectos mejorables y muy mejorables; razones de no compra.

\section{Logística}

Características de negocio; caracterización de compra. 

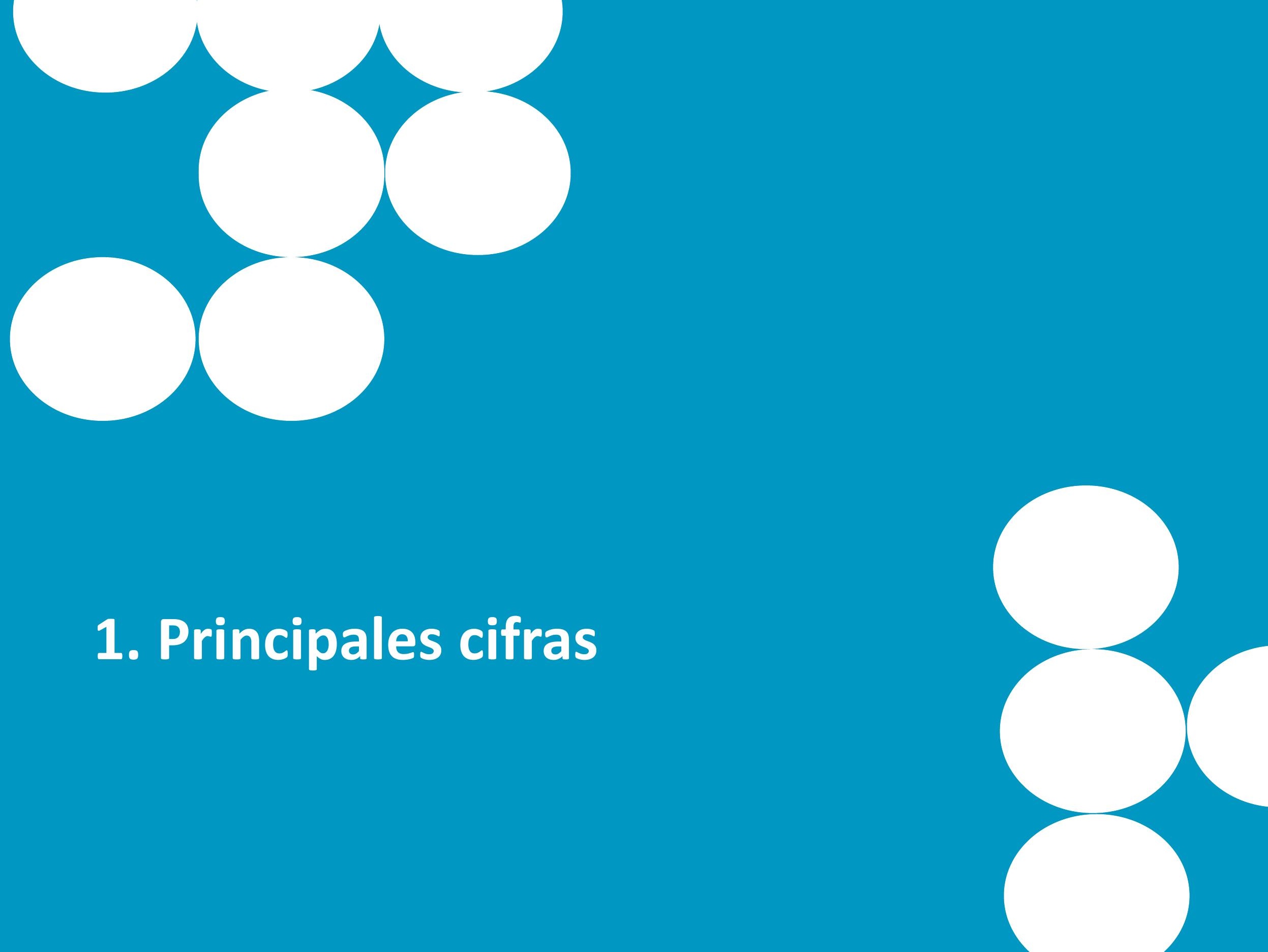


\section{Cifras Generales del B2C}

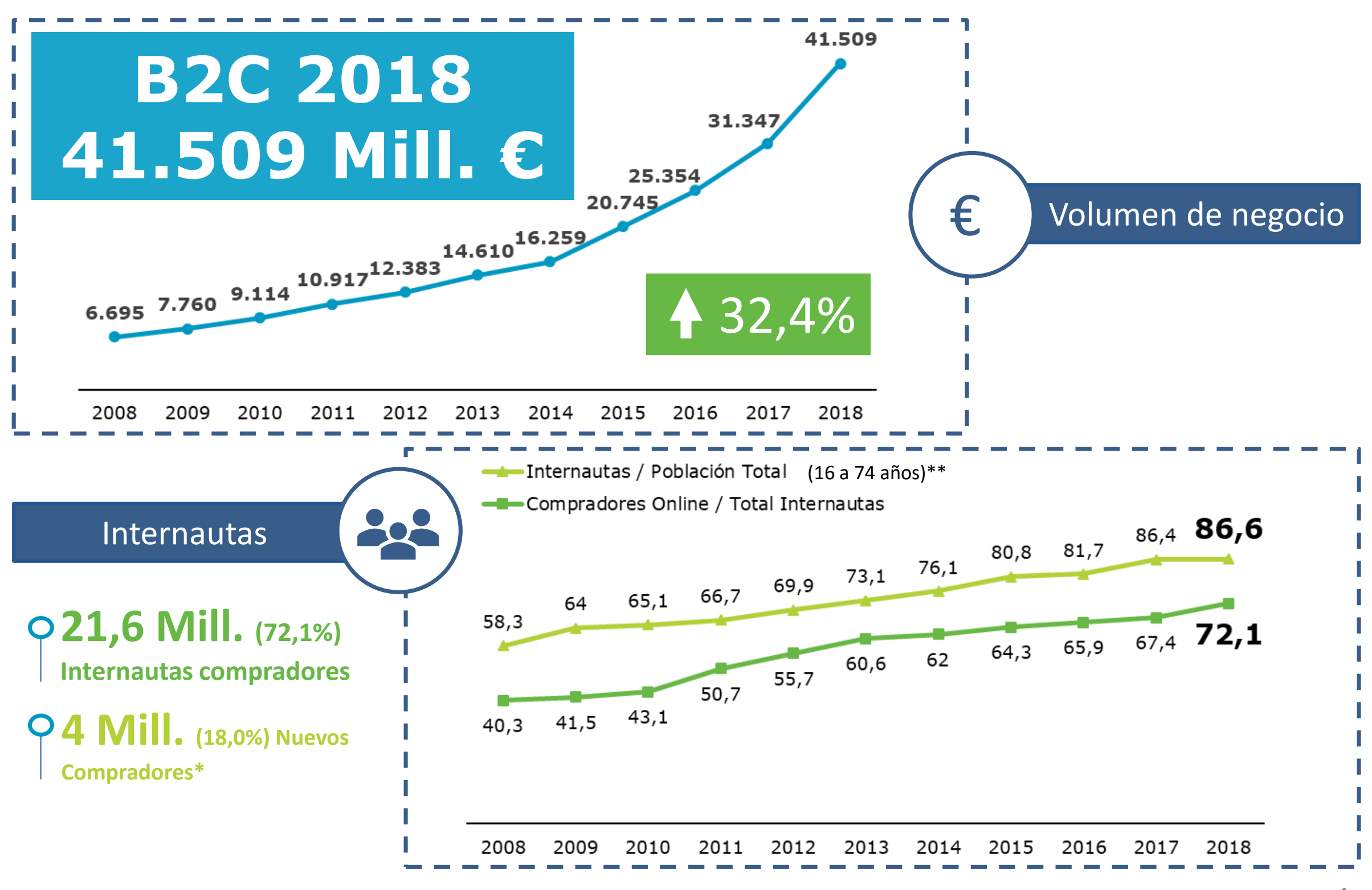




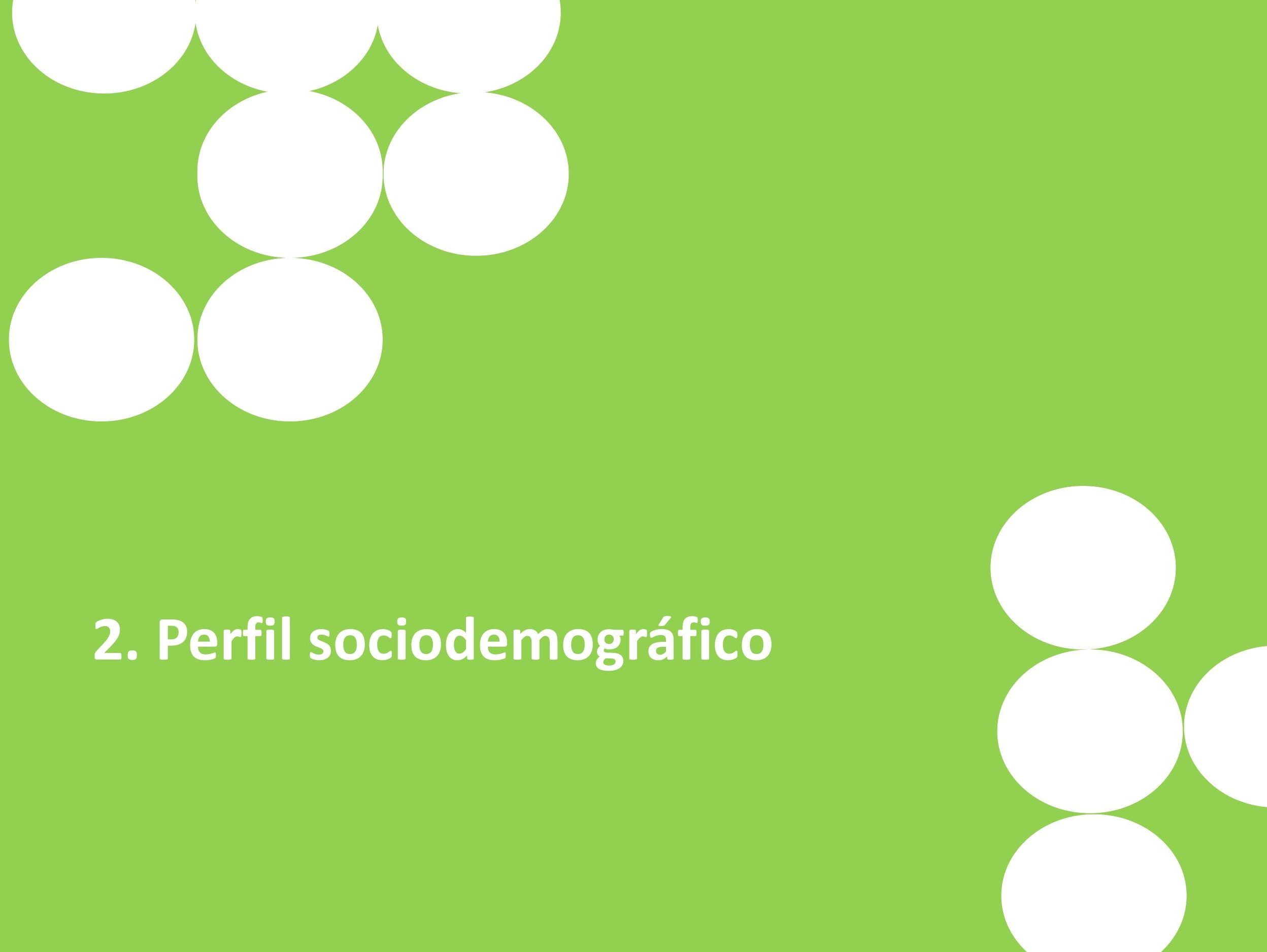




\section{Perfil sociodemográfico}

ontsi

red.es

\section{INTERNAUTAS}

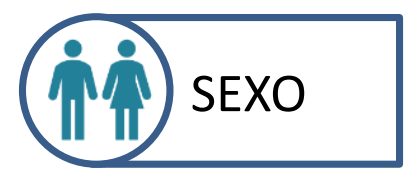

(iำ EDAD
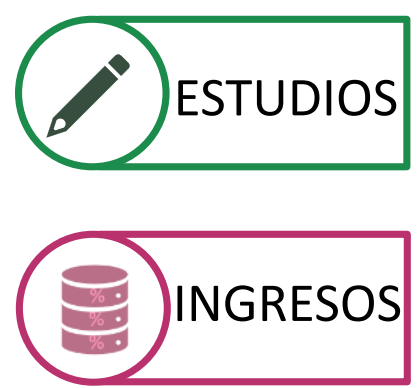

圅围 HÁBITAT

\section{Mujeres \\ $50,4 \% \triangle \begin{aligned} & 0,8 \\ & \text { P.P. }\end{aligned}$}

De 45 a 64 años

$42,2 \%$

Superiores

$47,0 \%$

900- 2.499 euros

$54,4 \%$

Más de 100.000

$40,9 \%$
INTERNAUTAS

COMPRADORES*

Mujeres

$52,0 \%>\begin{aligned} & 5,0 \\ & \text { P.P. }\end{aligned}$

De 35 a 54 años

44, $9 \%$

Superiores

$50,5 \%$

900- 2.499 euros

$54,6 \%$

Más de 100.000

$39,5 \%$
INTERNAUTAS NO COMPRADORES**

Hombres

$53,7 \%$ P.P.

De 55 a 74 años

$$
47,9 \%
$$

Superiores

$37,8 \%$

Menos 900- 2.499 euros

$78,1 \%$

Más de 100.000

$44,4 \%$ 


\section{Frecuencia y procesos de compra}

ontsi red.es

№ de procesos de compra

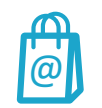

Entre 1 y 2 veces

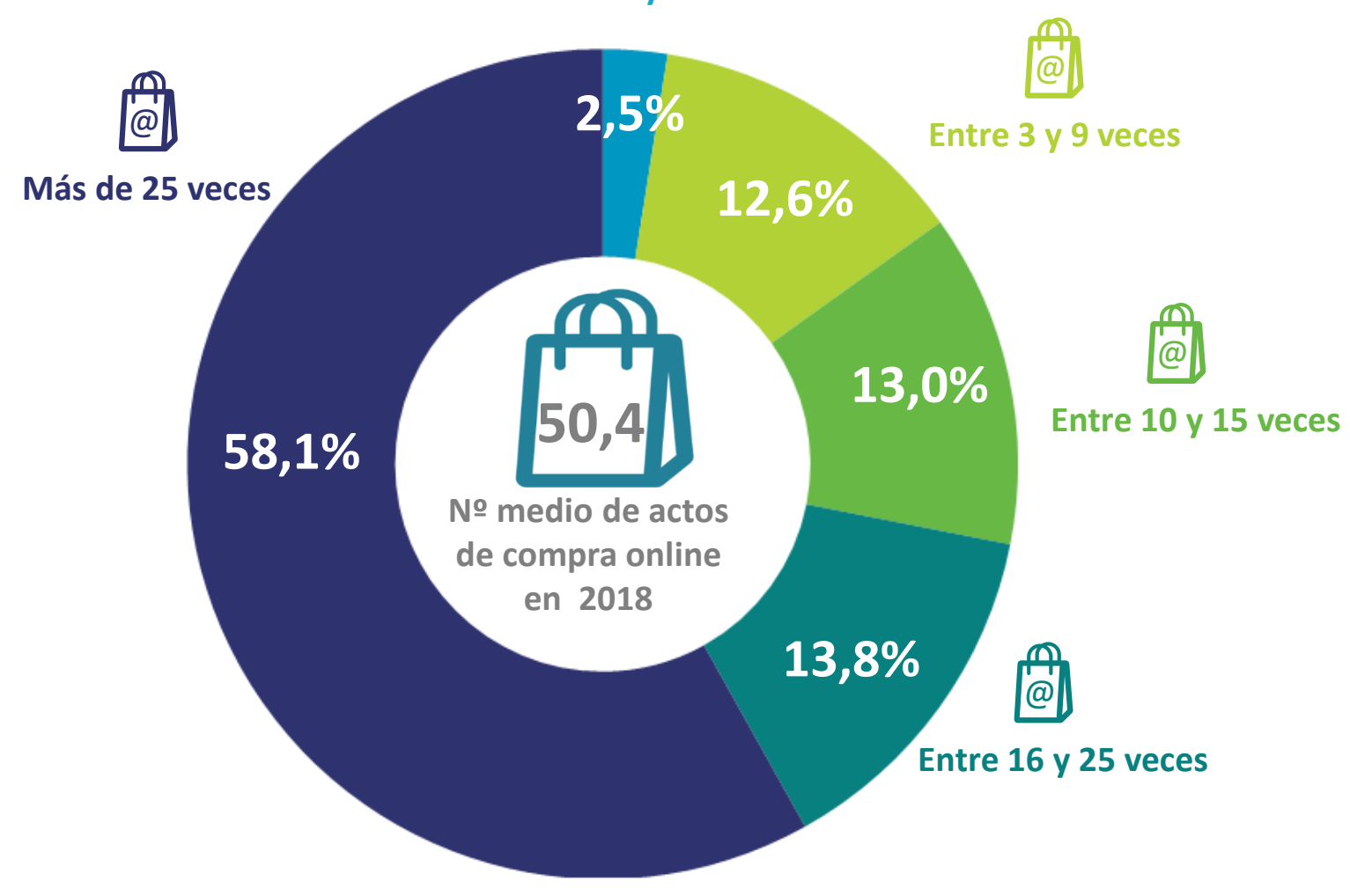

Base: internautas compradores
№ de categorías compradas

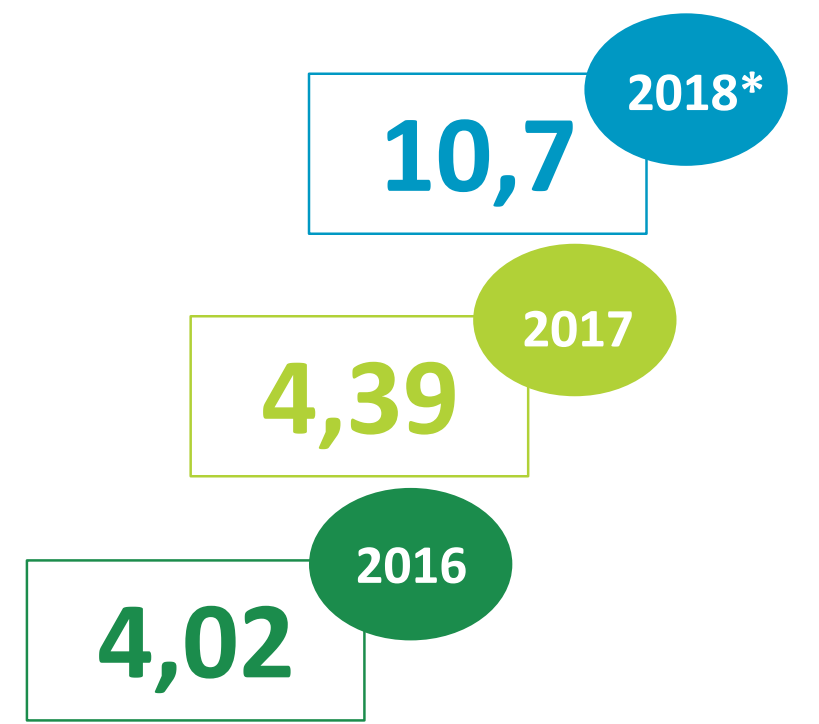

Nota*: Para la edición 2018 se han incorporado nuevas categorías a la lista de productos 


\section{Productos más adquiridos}

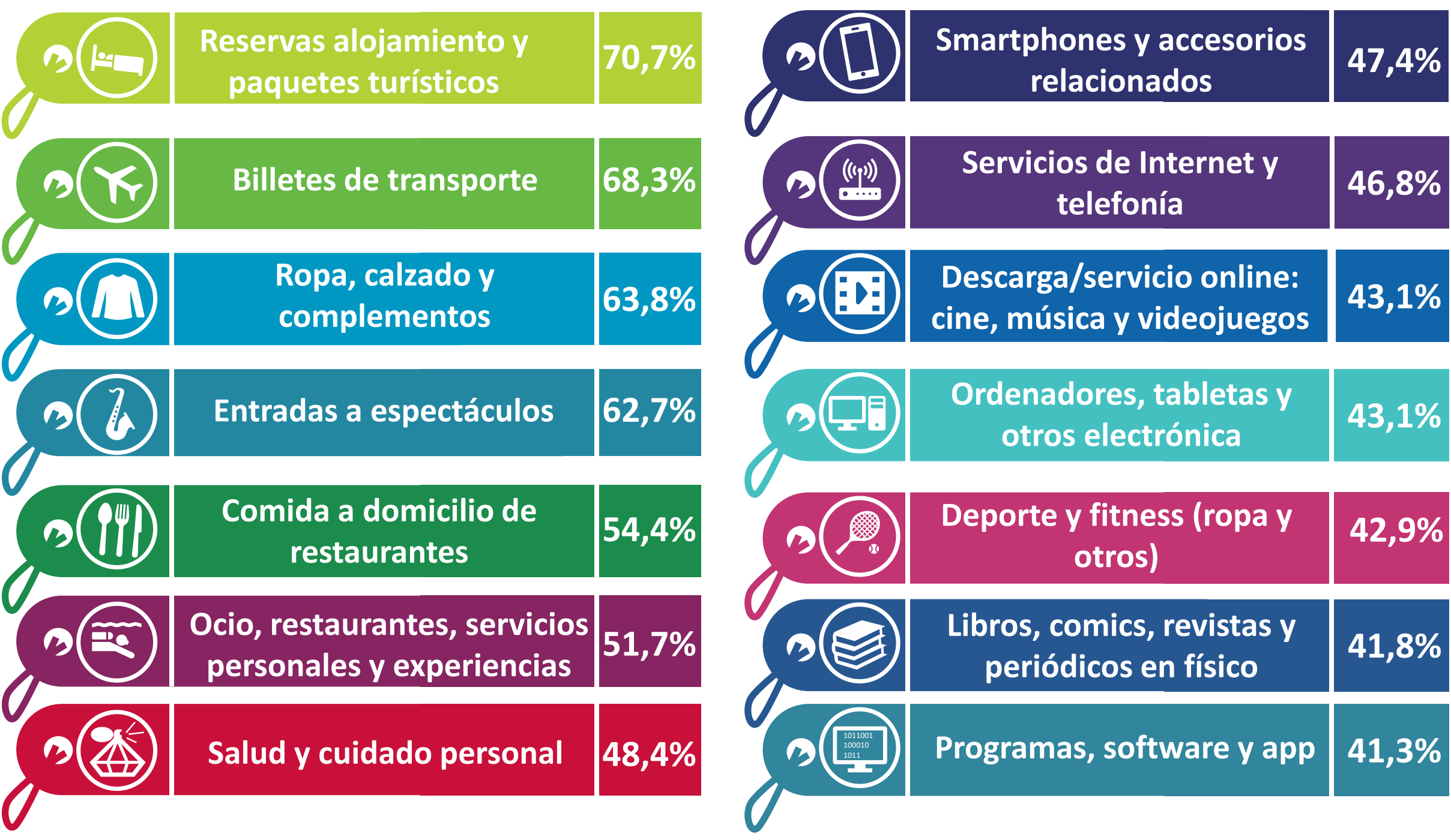

La descarga o servicio online de películas, música y videojuegos, es el producto que más se ha extendido entre los internautas compradores online (+35 p.p.) 


\section{Productos más adquiridos}

ontsi red.es

Principales productos Mujeres (\%)

Ropa, calzado y complementos
Reservas alojamiento y paquetes turísticos
Billetes de transporte
Entradas a espectáculos
Salud y cuidado personal

Diferencias en penetración de productos en favor de la Mujer

\begin{tabular}{|c|c|}
\hline Salud y cuidado personal & 15,7 \\
\hline Ropa, calzado y complementos & 11,5 \\
\hline $\begin{array}{l}\text { Libros, comics, revistas y } \\
\text { periódicos en físico }\end{array}$ & 8,9 \\
\hline
\end{tabular}

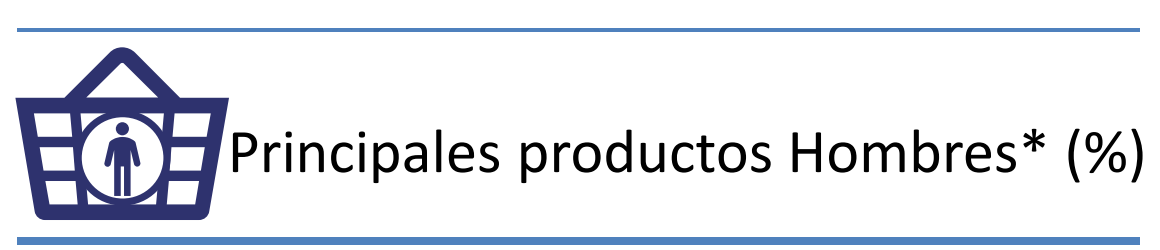

\begin{tabular}{l} 
Reservas alojamiento y paquetes turísticos \\
\hline Billetes de transporte \\
\hline Entradas a espectáculos
\end{tabular}

Diferencias en penetración de productos en favor de los Hombres

Programas, software y app
$\begin{aligned} & \text { Juegos de azar, concursos, } \\ & \text { apuestas y lotería }\end{aligned}$
Artículos de coleccionismo y antigüedades




\section{Sitios de compra}

\section{Sitios de compra}

Portales de venta online de múltiples vendedores

App oficial empresa/marca vendedora

$$
46,6 \%-\begin{gathered}
18,4 \\
\text { P.P. }
\end{gathered}
$$

Tiendas/empresas venta online y offline $46,0 \%$

Supermercados/grandes superficies venta online $y$ offline

$45,0 \%$

$39,4 \%$

Comparador o agregador

$21,7 \%$

Web ofertas y

cupones

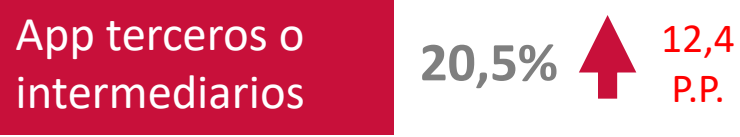

Webs/ clubes

de venta

$17,1 \%$

privada

Subastas

$16,3 \%$

\section{Redes}

sociales

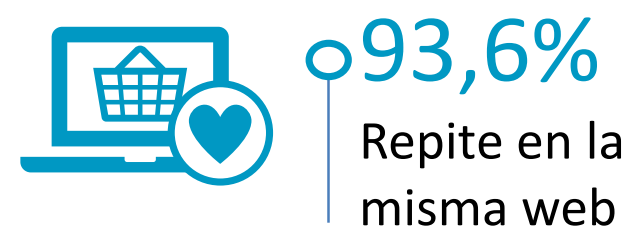

Razones para repetir web
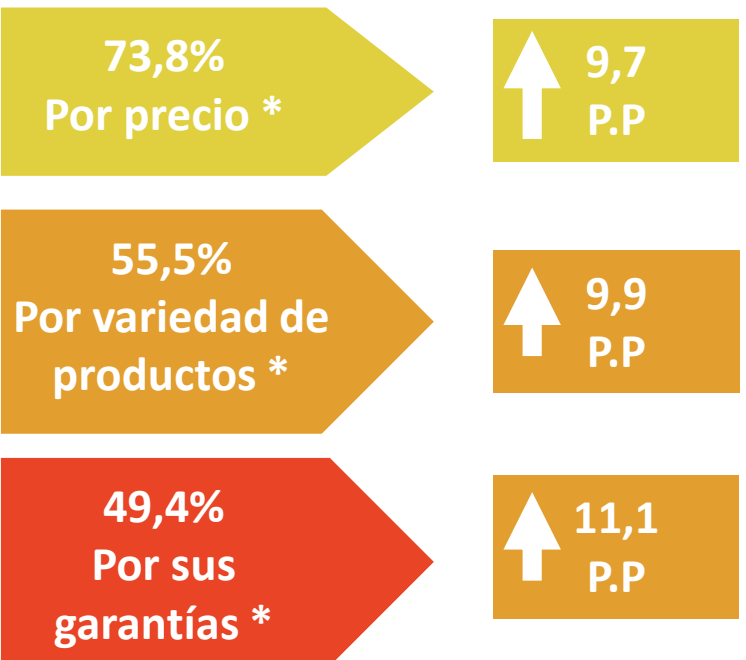


\section{Dispositivos de compra y contenidos digitales}

\% Compradores según los dispositivos utilizados en la compra

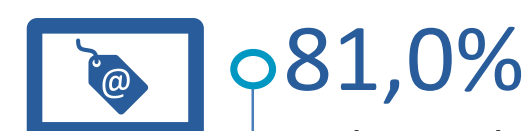

Utilizan el ordenador
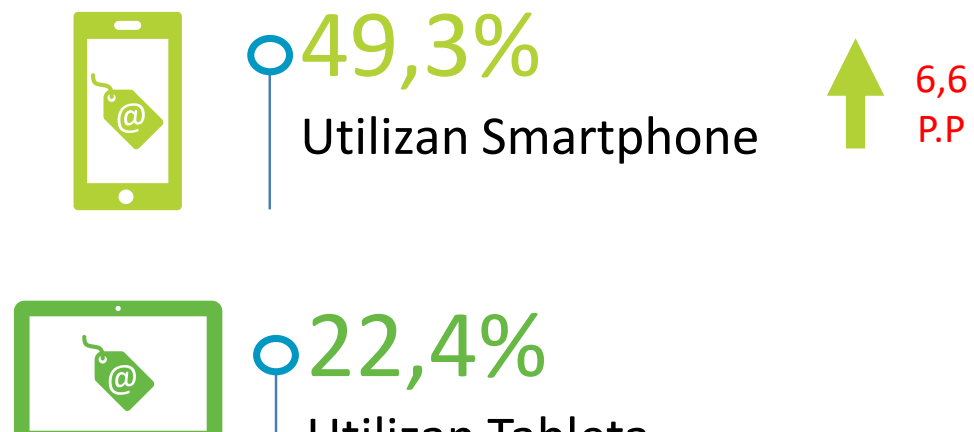
Utilizan Tableta

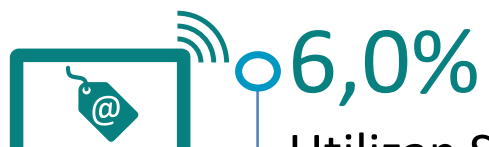
Utilizan Smart TV

o consola
Contenidos digitales y suscripciones
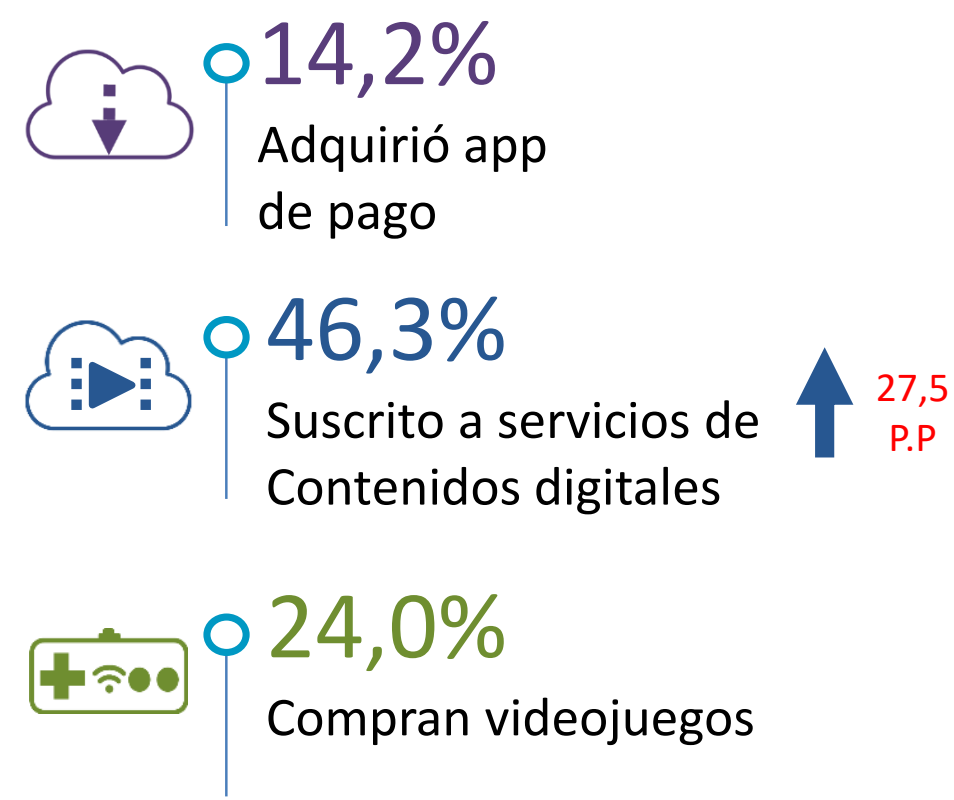


\section{Comercio online $\mathrm{C} 2 \mathrm{C}$ (Consumidor a consumidor)}

Herramientas de compraventa C2C online

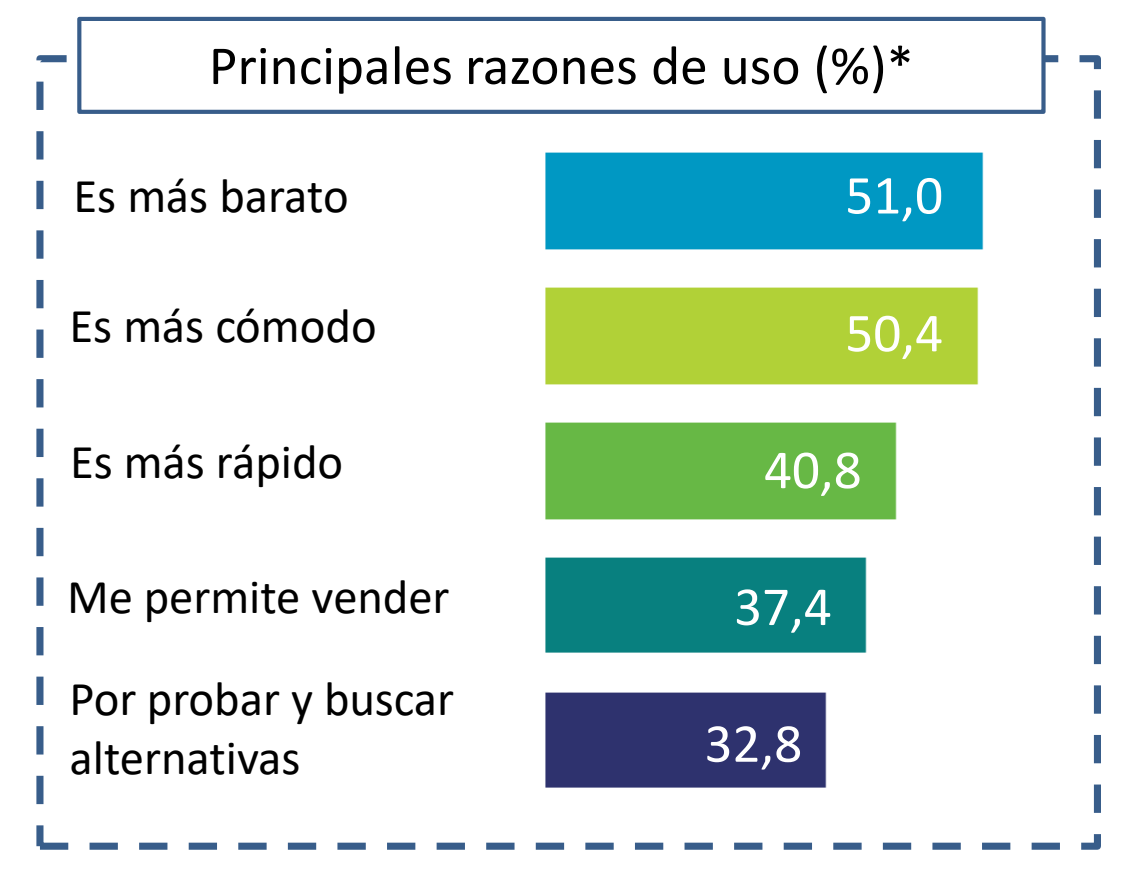

\section{2,5\% Utiliza algún tipo \\ $48,7 \%$ Utiliza \\ semanalmente*}

Micromecenazgo (crowdfunding) o donación a través de Internet 


\section{Incidencias y reclamaciones}

\section{Tipo de problemas*}

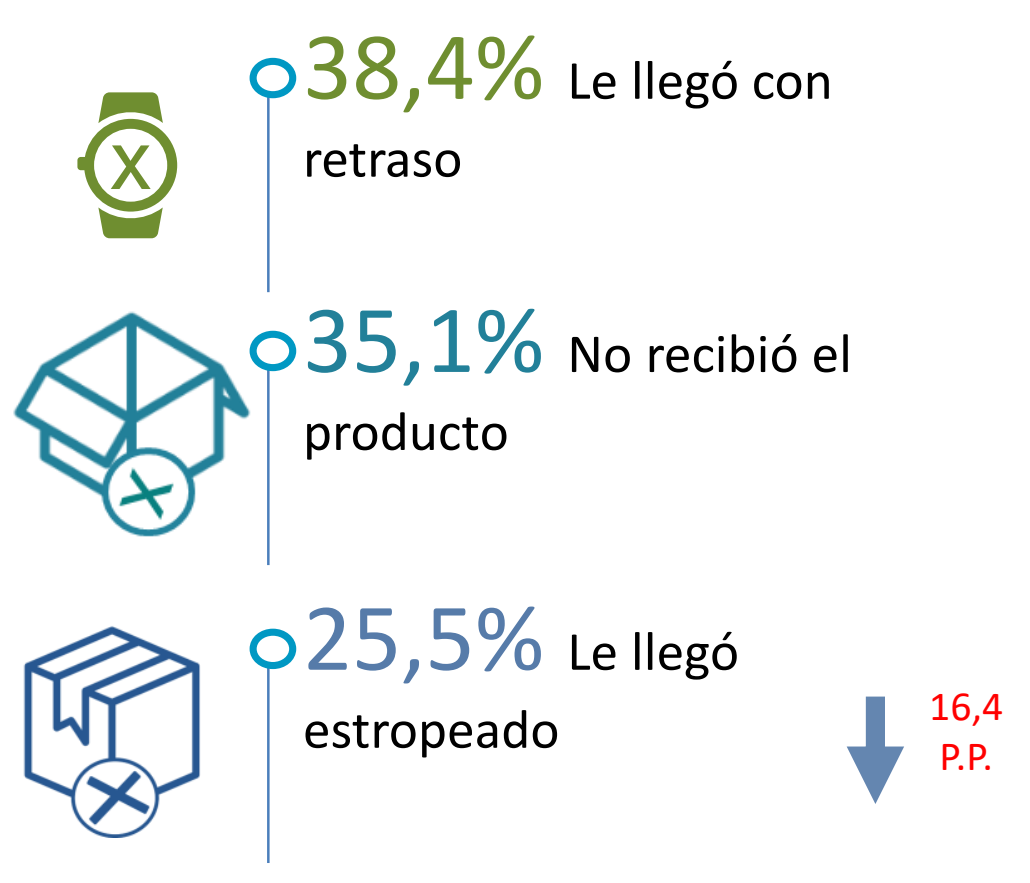

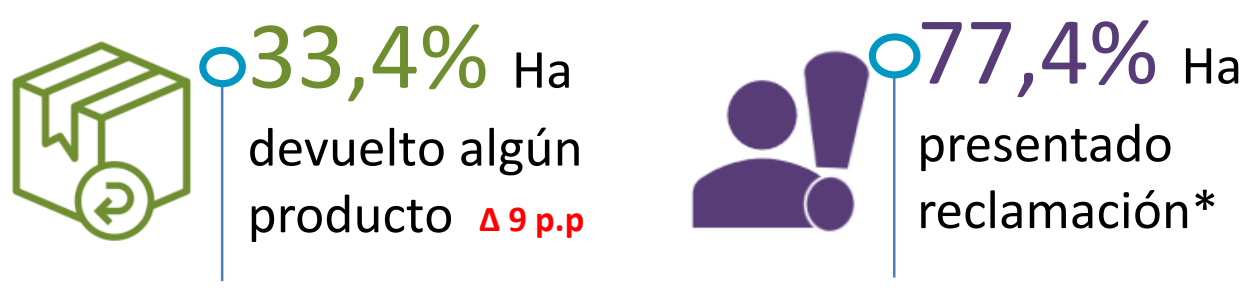

\section{Ante quién reclamó**}

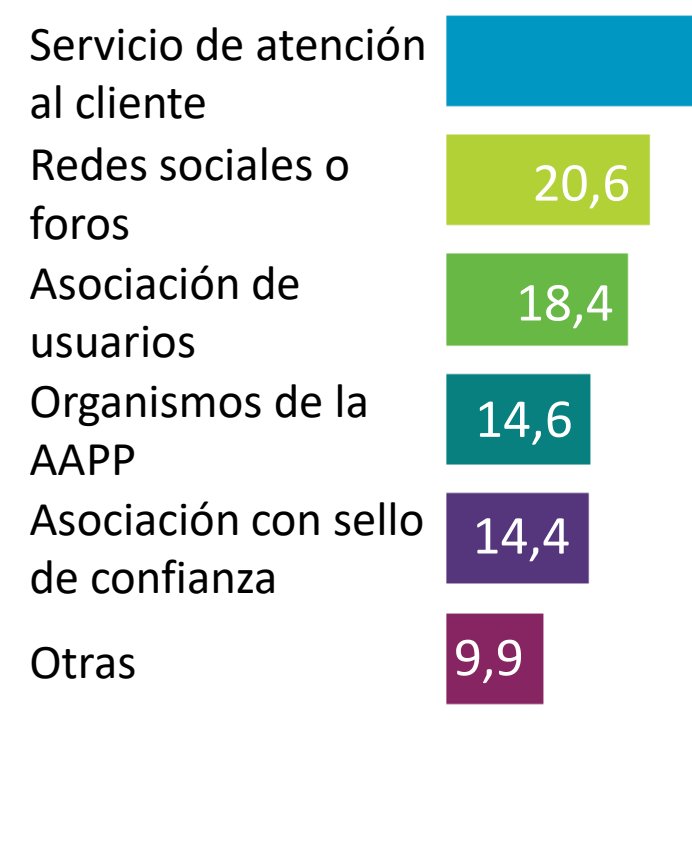

\section{2,9}




\section{Incidencias y reclamaciones}

\section{Devoluciones por producto}

Ropa, calzado y complementos

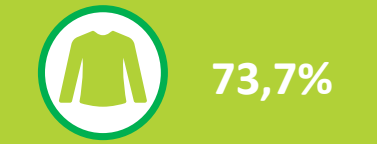

Ordenadores, tabletas, accesorios y otros productos de electrónica

प. $39,2 \%$
Vehículos de motor (alquiler y compra, repuestos y accesorios, y vehículos eléctricos)

Artículos de coleccionismo y antigüedades
$33,7 \%$

$30,8 \%$ 


\section{Perfil del gasto}

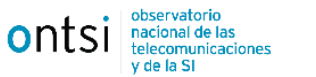

red.es

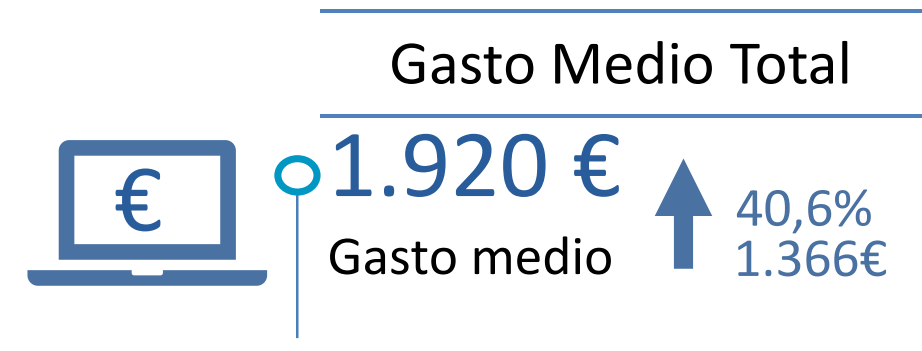

Gasto anual (\%)

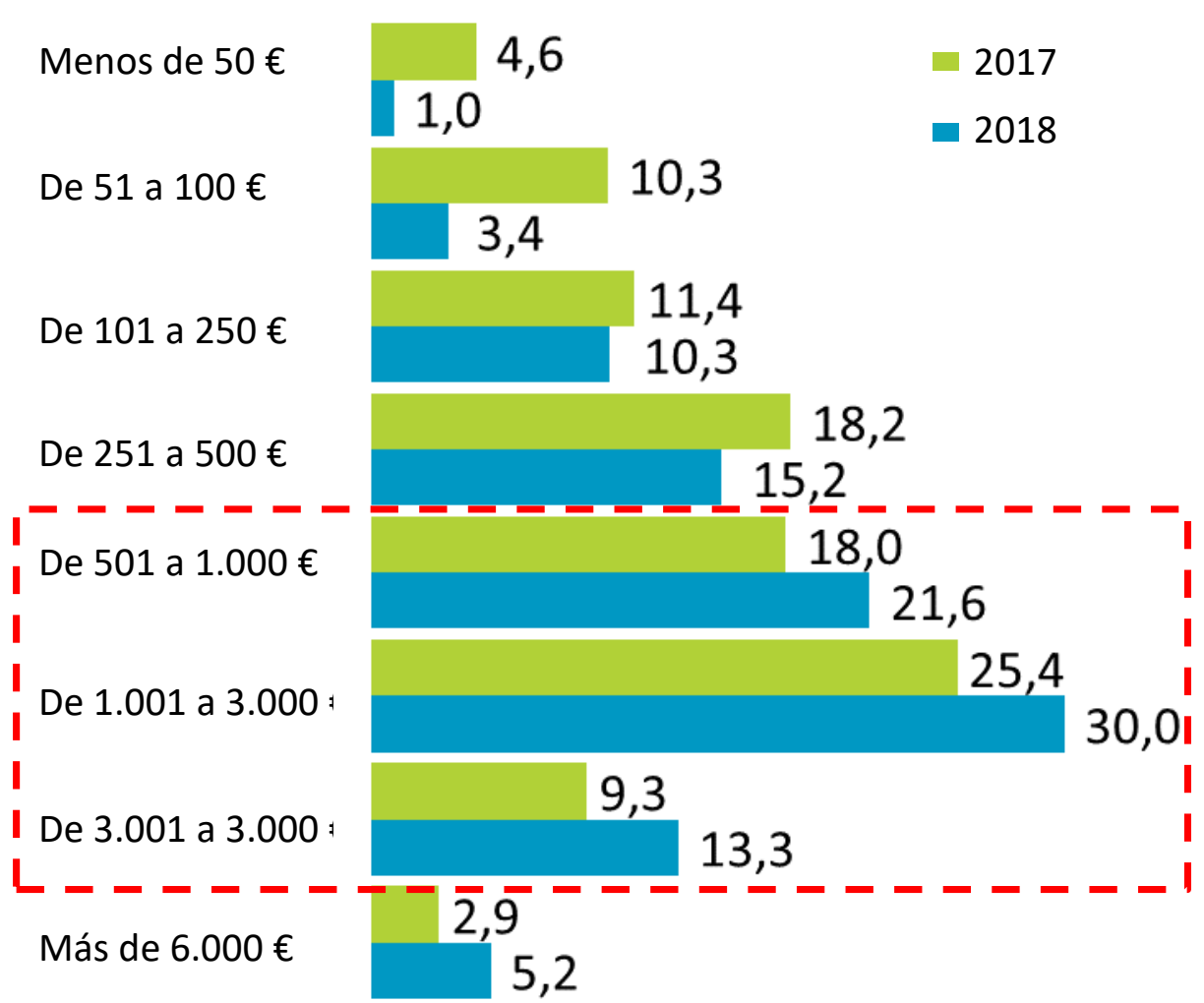

\section{Gasto medio anual por categoría $(€)$}

Reservas alojamiento y paquete turísticos

Billetes de transporte

Vehículos de motor (alquiler y compra, repuestos y accesorios, y vehículos eléctricos)

Ordenadores, tabletas, accesorios y otros productos de electrónica

Electrodomésticos, hogar y jardín

Deporte y fitness (ropa deportiva, accesorios y otros)

Alimentación, bebidas y productos de limpieza del hogar Smartphones y accesorios relacionados

Formación y cursos online

Joyería, bisutería y relojes

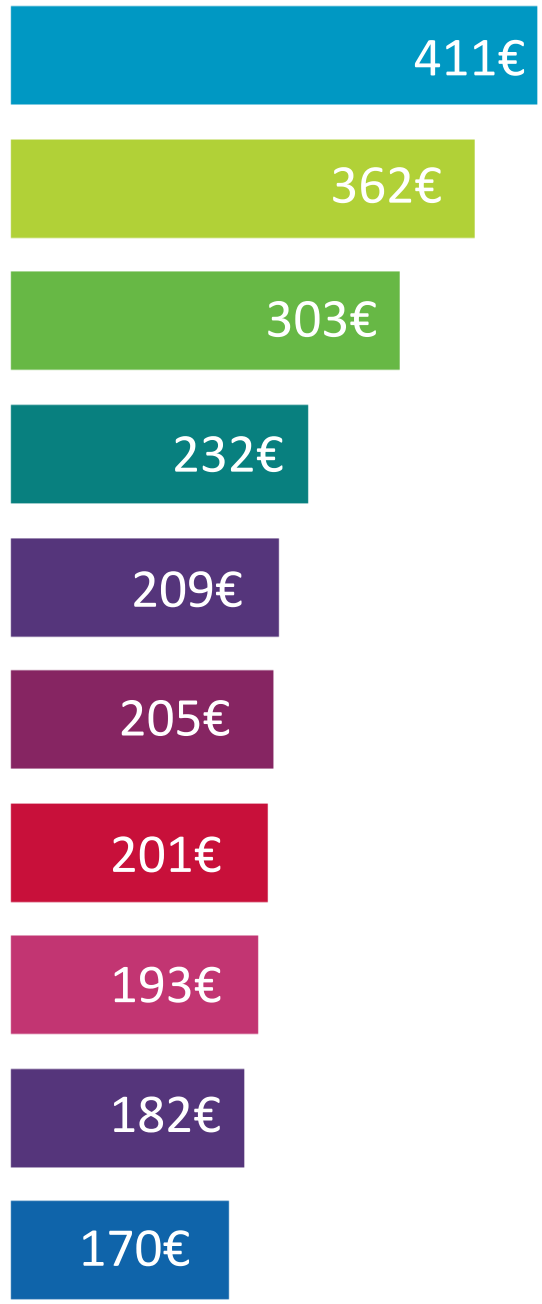




\section{Perfil del gasto}

Gasto Medio Mujeres

01.677 €
Gii)
Gasto medio
Gasto Medio Hombres

$2.183 €$

Gasto medio

Gasto medio anual por principales categorías (€)

\section{Mujeres}

Reservas alojamiento y paquete turístico

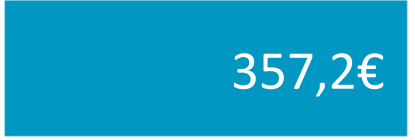

Vehículos de motor (alquiler y compra, repuestos y accesorios, y vehículos eléctricos)

Billetes de transporte

Deporte y fitness (ropa deportiva, accesorios y otros)

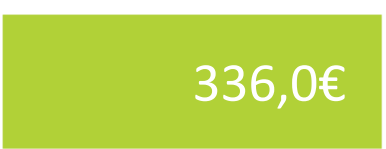

$285,6 €$

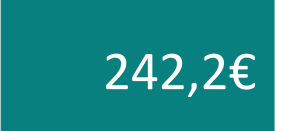

$199,1 €$

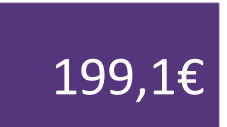

Reservas alojamiento y paquete turístico

Billetes de transporte

Vehículos de motor (alquiler y compra, repuestos y accesorios, y vehículos eléctricos)

Ordenadores, tabletas, accesorios y otros electrónica

Smartphones y accesorios relacionados
Electrodomésticos, hogar y jardín

\section{Hombres}
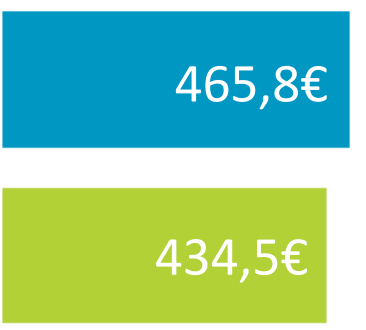

$273,7 €$

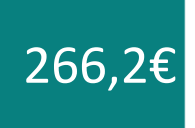

$220,4 €$ 


\section{Medios de pago}

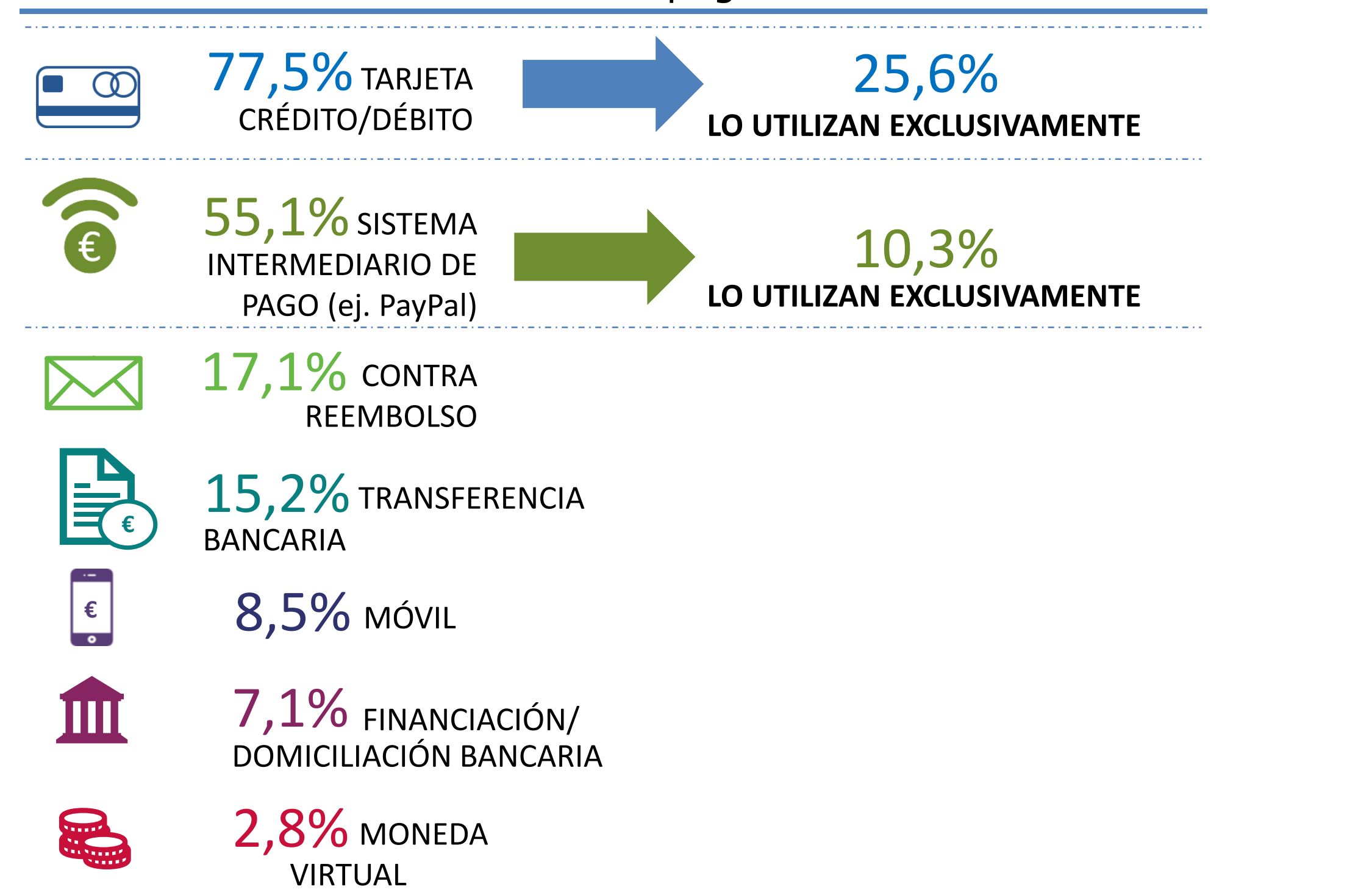




\section{Impulsores del comercio electrónico}

Destaca el aumento de relevancia del ahorro de tiempo

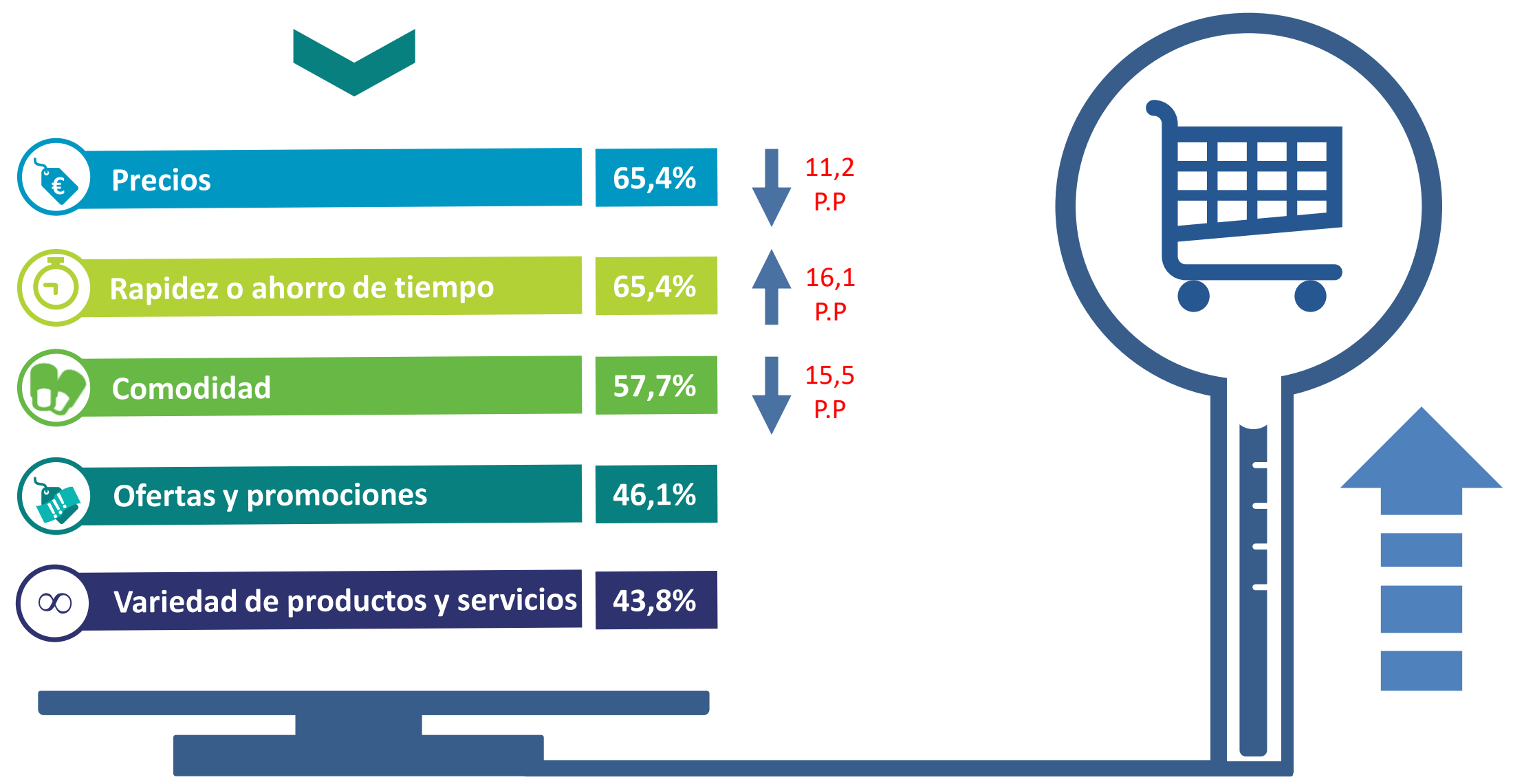




\section{Frenos al comercio electrónico}

\section{COMPRADORES}

Aspectos mejorables y muy mejorables

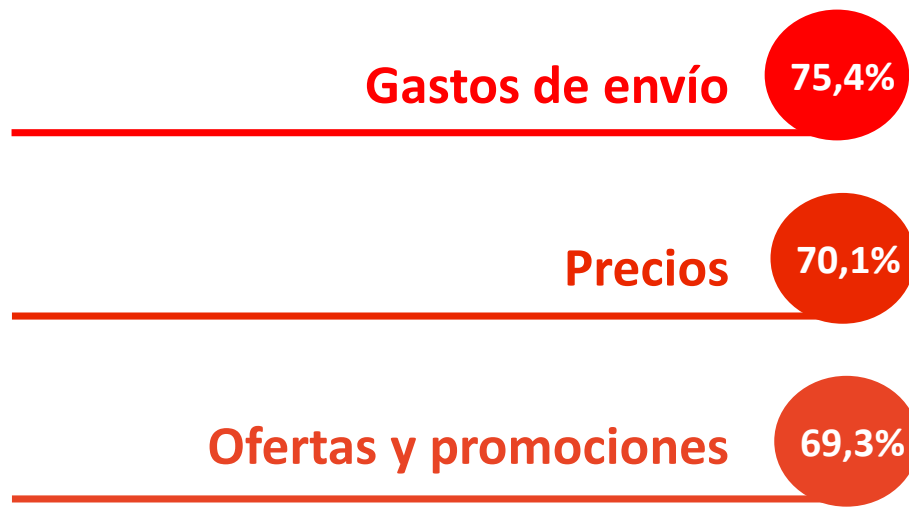

Condiciones, garantía de cambio y devolución

$67,1 \%$
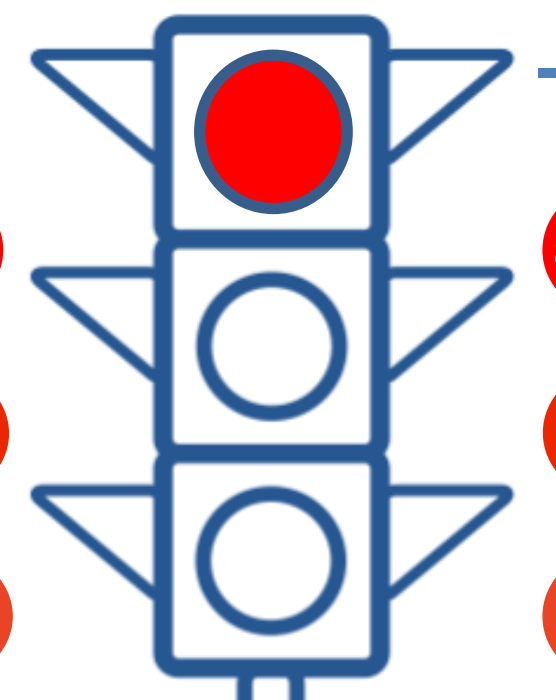

49,1\% Preferencia por la tienda física

$12,1 \%$

$52,3 \%$ Medio no seguro

Es complicado (no tiene Internet)

11,7\% Precios no baratos

\section{Razones de no compra}

$82,2 \%$ No lo necesita

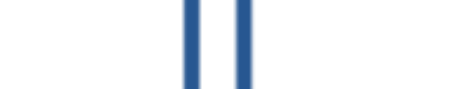

\section{NO COMPRADORES}

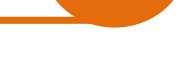

Uso de los datos personales

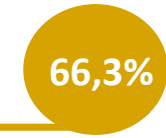

\section{FRENOS}




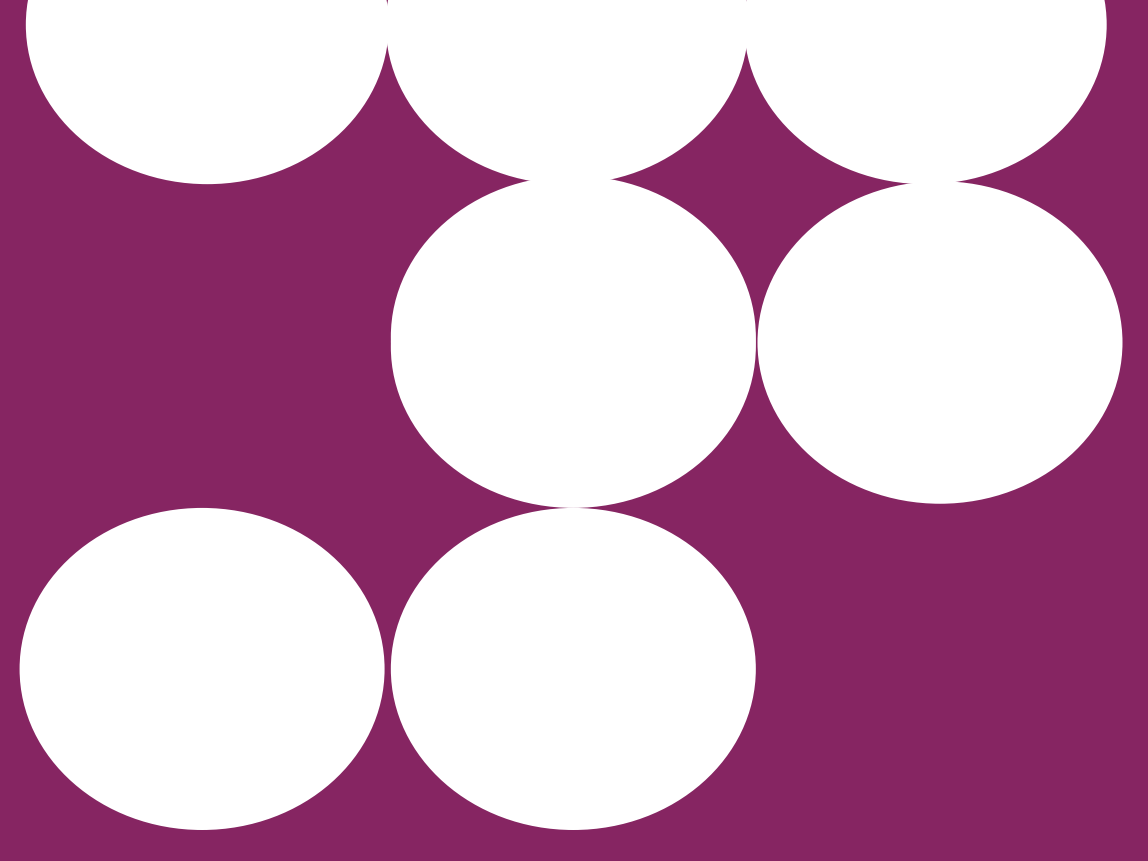

6. Logística

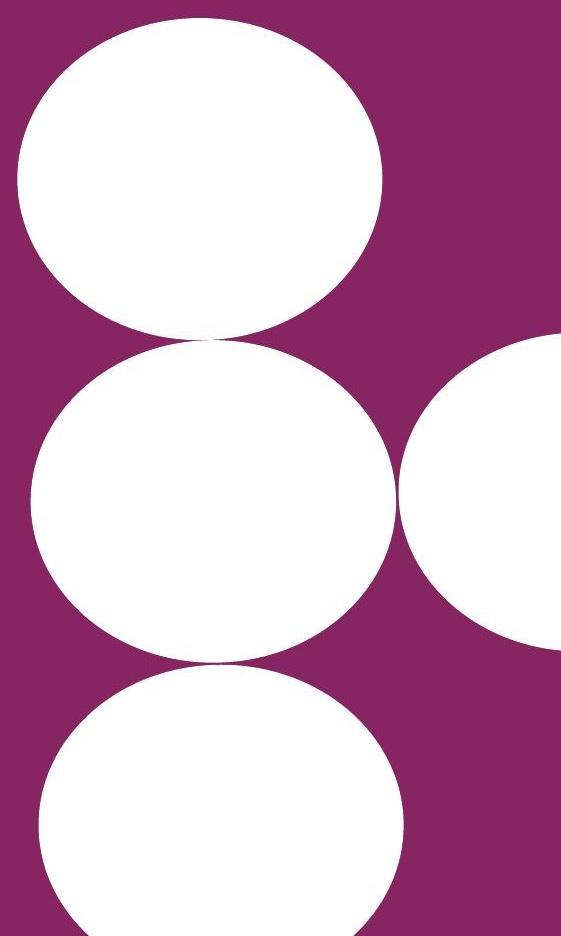




\section{Logística: Características de Negocio}

ontsi red.es

COMPRARON PRODUCTO REQUIERE ENVÍO FÍSICO

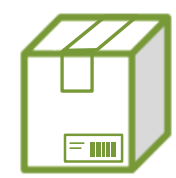

095,0\% compraron producto físico (con envío) $\Delta 15,7$ p.p
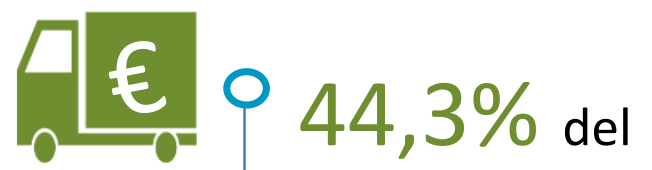
volumen total del e-commerce requiere envío físico 18.383 ммє

\section{NINGÚN PRODUCTO COMPRADO REQUIERE ENVÍO FÍSICO}

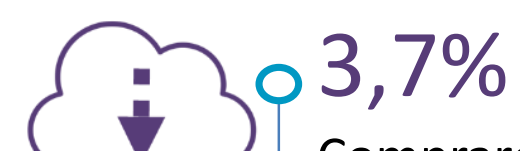

Compraron solo productos digitales (sin envío) $\nabla$ 14,9 p.p

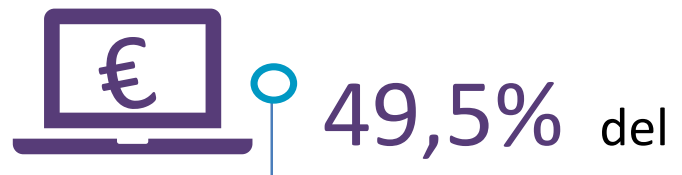

volumen total de ecommerce

20.557 ммє
INDEFINIDOS (OTROS Y NO SABE, NO CONTESTA)
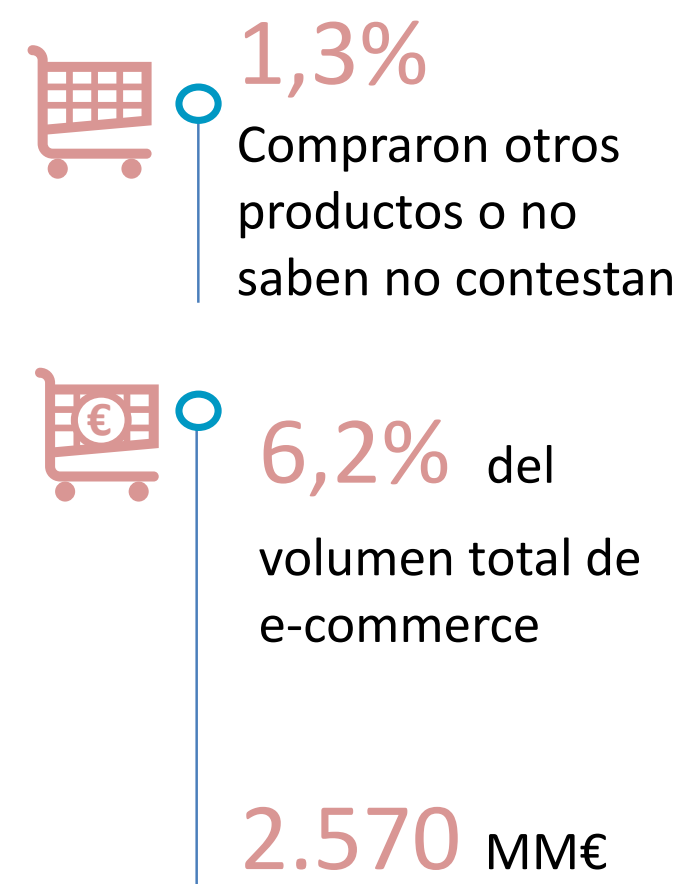


\section{Logística: Caracterización de compra}

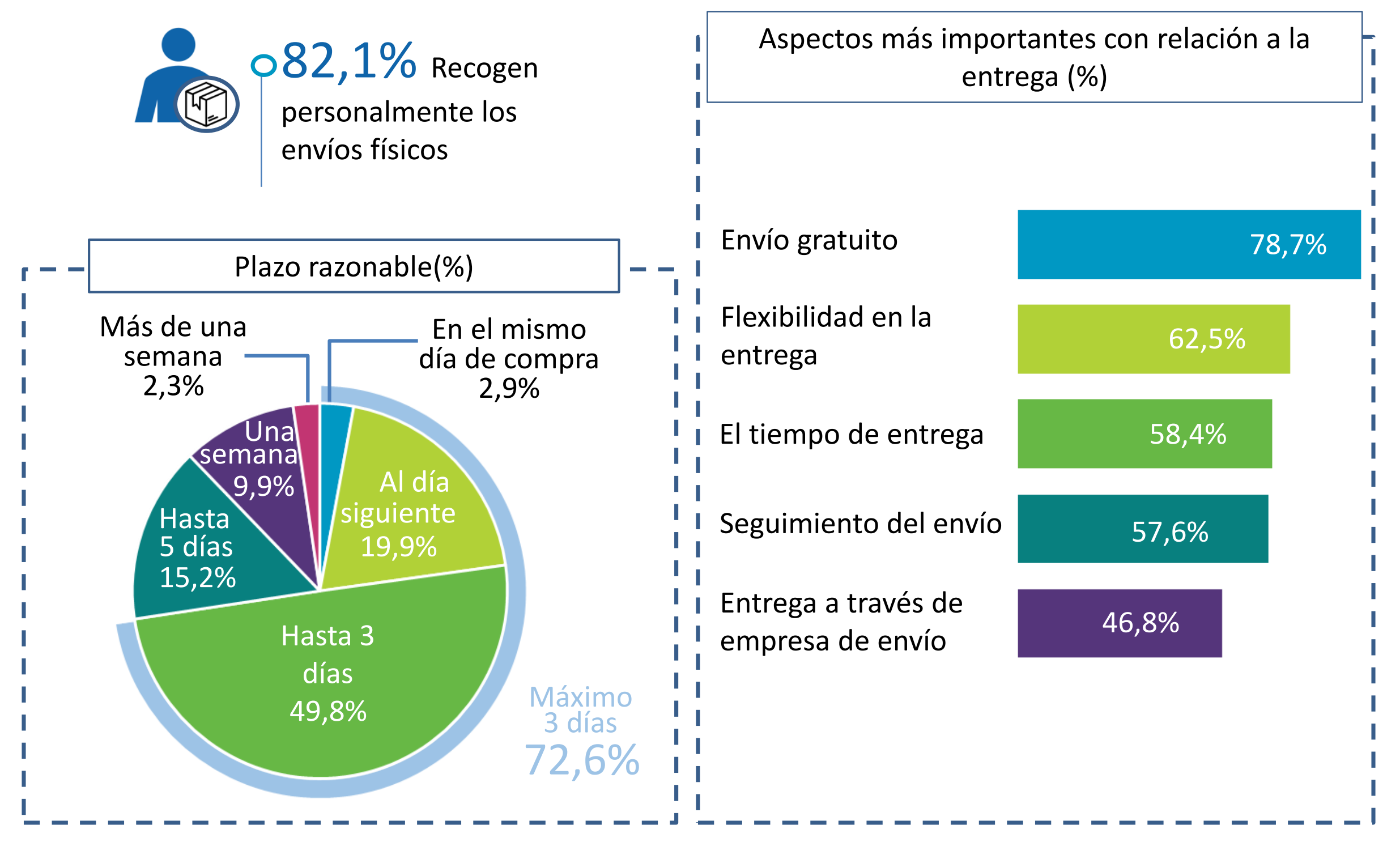




\section{Ficha técnica}

\section{Universo}

Total 29.997.557 individuos internautas.

Población de 16 a 74 años.

Fuente: Encuesta sobre equipamiento y uso

de tecnologías de información y

comunicación en los hogares (2018).INE.

Tamaño muestral

2.900

Recogida de información

Encuesta online (CAWI), a través de panel online.

Fechas de recogida de la información

Las encuestas se recogieron del 17 de junio al 28 de junio de 2019.

\section{Nota metodológica:}

Se debe tener en cuenta que la edición 2019 del informe "El Comercio Electrónico B2C en España. 2018” incluye cambios metodológicos:

- Universo: cambia de 15 y más años a 16 a 74 años (adaptación a INE).

- Cuestionario: Reformulación e inclusión de nuevas categorías de producto.

- Recogida de información: cambio de encuesta postal a encuesta online (CAWI). 


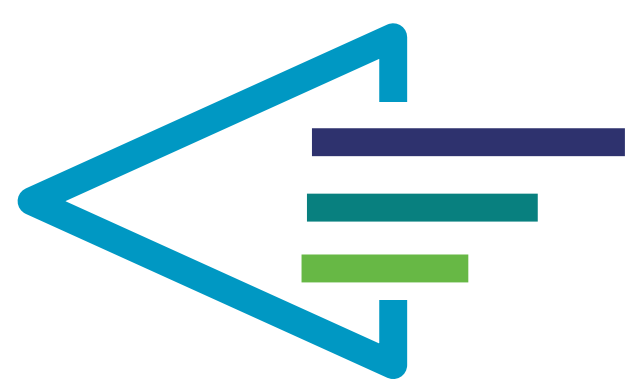

\section{Muchas gracias}

\section{ontsi observatorio \\ nacional de las \\ telecomunicaciones $y$ de la SI \\ red.es}

